\title{
Adoption of rice varieties. 2. Accelerating uptake
}

Witcombe, J. R.; Khadka, K.; Puri, R. R.; Khanal, N. P.; Sapkota, A.; Joshi, K. D.

\section{Experimental Agriculture}

DOI:

$10.1017 / \mathrm{S} 0014479716000624$

Published: 01/10/2017

Peer reviewed version

Cyswllt i'r cyhoeddiad / Link to publication

Dyfyniad o'r fersiwn a gyhoeddwyd / Citation for published version (APA):

Witcombe, J. R., Khadka, K., Puri, R. R., Khanal, N. P., Sapkota, A., \& Joshi, K. D. (2017). Adoption of rice varieties. 2. Accelerating uptake. Experimental Agriculture, 53(4), 627-643. https://doi.org/10.1017/S0014479716000624

\section{Hawliau Cyffredinol / General rights}

Copyright and moral rights for the publications made accessible in the public portal are retained by the authors and/or other copyright owners and it is a condition of accessing publications that users recognise and abide by the legal requirements associated with these rights.

- Users may download and print one copy of any publication from the public portal for the purpose of private study or research.

- You may not further distribute the material or use it for any profit-making activity or commercial gain

- You may freely distribute the URL identifying the publication in the public portal ?

Take down policy

If you believe that this document breaches copyright please contact us providing details, and we will remove access to the work immediately and investigate your claim. 


\title{
ADOPTION OF RIGE VARIETIES. 2. AGGELERATING UPTAKE
}

\author{
By J. R. WITCOMBE $\dagger \ddagger$, K. KHADKA $\ddagger$ R. R. PURI $\ddagger$, N. P. KHANAL $₫$,
} A. SAPKOTA $\S$ and K. D.JOSHI $\dagger \dagger$

$\dagger$ CAZS Natural Resources, Bangor University currently School of Environment, Natural Resources and Geography (SENRGY), Bangor University, Groynedd LL57 2UW, UK, $\ddagger$ Local Initiatives for Biodiversity, Research and Development (LI-BIRD), P.O. Box 324, Pokhara, Nepal, currently

National Wheat Research Programme, Nepal Agricultural Research council, Nepal, §Forum for Rural Welfare and Agricultural Reform for Development (FORWARD), Bharatpur, Nepal, -Currently CIMMTT South Asia Regional Office, P. O. Box 5186, Kathmandu, Nepal and ††CAZS Natural Resources, Bangor University c/ o CIMMTT South Asia Regional Office, P. O. Box 5186, Kathmandu, currently CIMMYT Pakistan, CSI complex, NARC Park Road 44000, Islamabad, Pakistan

\section{(Accepted 3 September 2016; First published online 11 October 2016)}

\section{SUMMARY}

\begin{abstract}
Plant breeding makes genetic gains over years, so growing newer varieties generally provides greater benefits than growing older ones. However, in low-altitude districts of Nepal, a few rice varieties covered $75 \%$ of the rice area and were more than 20 years old (first paper in this series). We test here if this slow rate of adoption of new varieties could be accelerated using a participatory method, Informal Research and Development (IRD), where packets of seeds of new rice varieties are widely distributed to many farmers. From 2008 to 2011, over 117000 IRD packets were distributed in 18 districts of the Nepal Terai, including over 70000 of three released varieties from a client-oriented breeding (COB) programme in Nepal. The IRD significantly increased the adoption of the three COB varieties. The benefits obtained by farmers in a single growing season equal the costs of IRD, if for every 75 kits distributed an additional 1 ha is grown. This assumes that the new varieties produce a $10 \%$ increase in yield (lower than that evidenced in their release proposals). On an average, fewer than three IRD kits were distributed for each hectare of a new variety grown by farmers in 2011. Furthermore, the effectiveness of IRD could be increased 1.2 to 2.7 fold (depending on the COB variety) if the IRD distribution were to be restricted to the region where the variety was most accepted. The best comparison of IRD with extension by the conventional system was their popularity compared with similar-aged varieties that had been promoted in the two systems. The adoption of three COB varieties was about twicethat of three varieties from the National Rice Research Programme (NRRP) that were closest in release date to the COB varieties. Unlike cost effectiveness assessed by hectares grown per IRD kit distributed, this comparison can only indicate efficacy because, as well as extension method, many factors influenced the adoption rates of the COB and NRRP varieties. The costs of IRD are small, both relative to the cost of breeding new varieties and to the benefits gained; so it is one of the simplest and most cost-effective interventions to increase agricultural productivity.
\end{abstract}




\section{INTRODUCTION}

We investigate in this paper whether participatory methods could accelerate the adoption in farmers' fields in Nepal of more recent varieties that should be superior because of the annual genetic gains expected from continued plant breeding. Participatory varietal selection (PVS) typically employs intensive systems of on-farm participatory evaluation that involve frequent interactions between researchers and farmers to assess their preferences in new varieties (Joshi and Witcombe, 1996; Witcombe et al., 1996). We used a method that involved very limited monitoring and technical support from researchers to increase cost effectiveness - informal research and development (IRD) - a method that was initiated at the Lumle Agricultural Research Centre in the late 1980s (Joshi and Sthapit, 1990; Joshi et al., 1997).

The IRD programme promoted new varieties that were produced by clientoriented breeding (COB) (Witcombe et al., 2005). The Nepal COB programme used many fewer crosses than conventionally employed and large populations in the segregating generations that are desirable from plant breeding theory because they increase the probability of recovering rare, desirable transgressive segregants (Witcombe and Virk, 2001; Witcombe et al., 2013). Large populations also fit much better with farmer participation - farmers can grow one or two populations on large areas but require researcher assistance to grow many smaller populations.

In the Nepal breeding programme that began in 1997, selection in the segregating generations was done in farmers' fields, primarily in Chitwan district (Gyawali et al., 2002; Joshi et al., 2007; Witcombe et al., 2013). Grain quality was tested with the end users (farmers and consumers) before yield trials. Once an acceptable variety was identified it was immediately given to farmers to test in PVS trials by comparing it to the most preferred rice varieties they currently grew. The trials were in the villages where the project operated, predominantly in Chitwan and Nawalparasi districts.

In examining the impact of IRD, we made one of the largest survey on varietal adoption reported in the literature. We interviewed 3332 households of which 1605 concerned adoption in 2008 and 1787 adoption in 2011. This large sample size increased the reliability of our conclusions on the efficacy of IRD and on how varietal adoption varied with geographical area.

\section{MATERIALS AND METHODS}

\section{Varieties from client-oriented breeding}

The IRD programme (described below) included three varieties produced by COB that were officially released in Nepal (Table 1) and one COB variety, Barkhe 1027, that was registered (a slightly simpler process than release) in Nepal. Although other COB varieties were included in the IRD distribution (Table 2), we do not report on their adoption here.

\section{IRD distribution}

The Department for International Development (DFID) Research into Use Programme (RiUP) funded two projects in Nepal - a Rice Legume Project led by 
Table 1. The maturity, year of release, rice domain and some major traits of three released varieties produced by client-oriented breeding that were included in the IRD distribution.

\begin{tabular}{|c|c|c|c|c|}
\hline Variety & Maturity (days) & Year released & Rice domain & Major traits \\
\hline Barkhe 3004 & Late (157) & 2006 & $\begin{array}{l}\text { Medium and } \\
\text { lowland }\end{array}$ & High yield and disease resistance. \\
\hline $\begin{array}{l}\text { Sunaulo } \\
\text { Sugandha }\end{array}$ & Late (151) & 2008 & $\begin{array}{c}\text { Medium and } \\
\text { lowland }\end{array}$ & $\begin{array}{l}\text { Aromatic, excellent eating quality, very } \\
\text { high yield compared with other } \\
\text { aromatic varieties. }\end{array}$ \\
\hline Barkhe 2014 & Medium (140) & 2011 & Medium & $\begin{array}{l}\text { Similar to Kanchhi Mansuli but higher } \\
\text { yielding and earlier to mature. }\end{array}$ \\
\hline
\end{tabular}

Table 2. Summary of IRD seed packet distribution 2008 to 2011 by variety by two NGOs in 18 districts of the Nepal Terai.

\begin{tabular}{lrc}
\hline Variety & Total & Total (\%) \\
\hline Barkhe 3004 & 33915 & 30 \\
Sunaulo Sugandha & 29826 & 27 \\
Barkhe 3019 & 13924 & 12 \\
Barkhe 1027 & 13208 & 12 \\
Barkhe 2014 & 9084 & 8 \\
Judi 582 & 3434 & 3 \\
NRRP varieties* & 3600 & 3 \\
Others & 14575 & 5 \\
Grand total & 117966 & 100 \\
\hline
\end{tabular}

*Varieties shown in Table 5.

the non-government organisation (NGO) Local Initiatives for Biodiversity, Research and Development (LI-BIRD) and a Rainfed Rabi Cropping (RRC) Project led by the NGO Forum for Rural Welfare and Agricultural Reform for Development (FORWARD). Scientists from Bangor University, Bangor, UK, were partners in both projects.

Packets of rice seeds of the new rice varieties from the Nepal COB programme were distributed by these NGOs across 18 districts in the Terai from 2008 to 2011 (Figure 1, Table 2). In the IRD, farmers received either a 1 or $2 \mathrm{~kg}$ bag of seed (according to seed availability) of a single variety that usually contained a leaflet describing the varietal characteristics. In each village, the NGOs gave the bags of seeds to farmers' groups who distributed them to their members. In a minority of cases, the NGOs gave seed to staff in the Nepal District Agricultural Development Offices (DADOs) who supplied the seed to farmers groups or to government agricultural service centres that distributed them to farmers on a first-come, first-served basis. In all cases, records were kept of the recipient farmers.

Most seed was distributed in 2009 (41\%) and 2010 (32\%) with only 14\% in 2008 and $12 \%$ in 2011 . The distribution by district was also uneven and mostly determined by the location of project staff and availability of seed (Tables 3 and 4). 
Table 3. Distribution by district of IRD packets from 2008 to 2011 in 18 districts of the Terai ordered by number distributed.

\begin{tabular}{lrr}
\hline District & IRD seed packets (no) & Total (\%) \\
\hline Nawalparasi & 13679 & 12 \\
Jhapa & 12087 & 10 \\
Mahottari & 10845 & 9 \\
Bara & 8656 & 7 \\
Sunsari & 8626 & 7 \\
Sarlahi & 7833 & 7 \\
Rupandehi & 7248 & 6 \\
Dhanusha & 7120 & 6 \\
Morang & 6020 & 5 \\
Rautahat & 5585 & 5 \\
Tanahun & 5031 & 4 \\
Kapilbastu & 4191 & 4 \\
Kanchanpur & 3905 & 3 \\
Dang & 3820 & 3 \\
Saptari & 3680 & 3 \\
Banke & 3470 & 3 \\
Kailali & 3109 & 3 \\
Siraha & 3061 & 3 \\
Grand total & 117966 & 100 \\
\hline
\end{tabular}

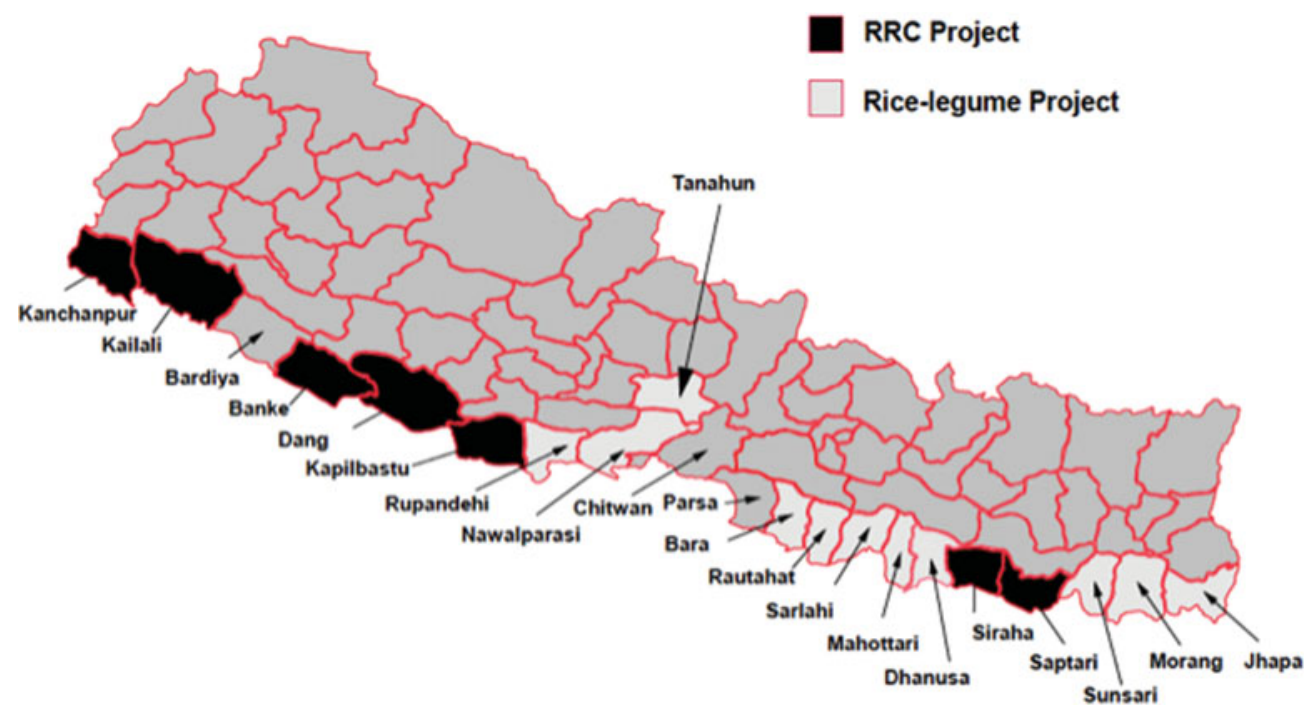

Figure 1. The districts where the rainfed rabi cropping and rice legume projects took place in Nepal, 2008 to 2011.

\section{Analysis of the cost effectiveness of IRD}

Which rice varieties households grew in 2011 and the proportion (\%) of the household rice area they occupied was assessed from a combined survey of 1787 households comprising 1318 households that had received IRD kits in 2008 and 469 households resampled from the 2008 baseline survey and interviewed again in 2011 
Table 4. Distribution of IRD packets from 2008 to 2011 of four released or registered $\mathrm{COB}$ varieties shown as percentage of total of each variety (e.g., $5 \%$ of the 13208 seed packets of Barkhe 1027 were distributed in Nawalparasi).

\begin{tabular}{|c|c|c|c|c|c|}
\hline Variety & $\begin{array}{c}\text { Barkhe } \\
3004 \\
(\%)\end{array}$ & $\begin{array}{c}\text { Sunaulo } \\
\text { Sugandha } \\
(\%)\end{array}$ & $\begin{array}{c}\text { Barkhe } \\
2014 \\
(\%)\end{array}$ & $\begin{array}{c}\text { Barkhe } \\
1027 \\
(\%)\end{array}$ & $\begin{array}{c}\text { Grand } \\
\text { Total } \\
(\%)\end{array}$ \\
\hline Nawalparasi & 13 & 17 & & 5 & 12 \\
\hline Jhapa & 17 & 4 & 11 & 2 & 9 \\
\hline Mahottari & 11 & 12 & 6 & 2 & 9 \\
\hline Sarlahi & 16 & 7 & 1 & 1 & 9 \\
\hline Rupandehi & 5 & 7 & 3 & 14 & 7 \\
\hline Bara & 3 & 11 & 6 & 9 & 7 \\
\hline Rautahat & 4 & 13 & & & 6 \\
\hline Dhanusha & 7 & 3 & 7 & 8 & 6 \\
\hline Sunsari & 10 & & 6 & 3 & 5 \\
\hline Morang & 4 & & 7 & 13 & 4 \\
\hline Tanahun & 4 & 6 & & 4 & 4 \\
\hline Kapilbastu & 1 & 5 & 10 & 6 & 4 \\
\hline Kanchanpur & 1 & 3 & 9 & 6 & 3 \\
\hline Dang & 1 & 8 & & & 3 \\
\hline Banke & 1 & 4 & 6 & 6 & 3 \\
\hline Saptari & 1 & & 10 & 10 & 3 \\
\hline Kailali & & 2 & 8 & 6 & 2 \\
\hline Siraha & 1 & & 9 & 6 & 2 \\
\hline Grand total (no packets) & 33915 & 29826 & 9084 & 13208 & 86033 \\
\hline Proportion (\%) & 39 & 35 & 11 & 15 & \\
\hline
\end{tabular}

(details in the first paper in this series). From this, the adoption of COB varieties in 2011 across 18 Terai districts was determined.

To analyse the cost effectiveness of IRD, we determined the ratio of the amount of seed supplied of the COB varieties in IRD kits to the amount of increased grain harvest from growing higher yielding $\mathrm{COB}$ varieties. For each district, the percentage of rice area devoted to the $\mathrm{COB}$ varieties by the surveyed households was calculated from the survey data for 2011 and multiplied by the total rice area in each district from government statistics. This estimated the adoption area (ha) of the COB varieties by district that was then multiplied by the assumed increase in grain yield ha ${ }^{-1}$. We used a conservative estimate of an increased grain harvest of $10 \%$, lower than the average of 13\% yield increases found in PVS trials. Barkhe 2014 yielded 19\% more than Kanchhi Mansuli the most similar of existing varieties. Aromatic variety Sunaulo Sugandha yielded 13\% more than the similar duration but non-aromatic standard check Masuli, and considerably more than 13\% compared with aromatic landraces. Barkhe 3004 yielded 7\% more than Masuli in PVS and on station trials. A 10\% yield advantage would give an average benefit of $300 \mathrm{~kg} \mathrm{ha}^{-1}$ when average rice yields of 3 $\mathrm{t} \mathrm{ha}^{-1}$ are assumed. This $10 \%$ advantage also did not account for the higher value of the aromatic grain of Sunaulo Sugandha grain compared with that of non-aromatic varieties such as Masuli. To estimate seed supplied, we conservatively assumed the kits were all of $2 \mathrm{~kg}$ (some were $1 \mathrm{~kg}$ ). 
Table 5. The maturity, year of release and rice domain of three NRRP varieties released for the Terai used as a comparison.

\begin{tabular}{lccl}
\hline Variety & Maturity (days) & Year released & Rice domain \\
\hline Ram Dhan & 133 & 2006 & Medium \\
Mithila & 145 & 2006 & Medium and low \\
Loktantra & 130 & 2006 & Medium and upland \\
\hline
\end{tabular}

We then compared the actual adoption with the minimum adoption required for costs to be covered by benefits. Seed input of IRD equals the amount of additional grain obtained when 150 IRD kits produce 1 ha of earlier adoption (i.e., $300 \mathrm{~kg}$ of seed supplied and an additional harvest of $300 \mathrm{~kg}$ from $1 \mathrm{ha}$ ). The additional costs of the IRD distribution were accounted for by doubling the cost of the IRD seed compared with the value of the additional harvested grain. IRD distribution costs were mostly comprised of the purchase cost of the seed and its transport when it is assumed that the infrastructure and staff costs in the extension services are already in place. With these assumptions, the costs of IRD approximately equal the benefits when 75 IRD kits lead to the adoption of 1 ha. If substantially less than 75 IRD kits are required to cause 1 ha of earlier adoption, it can be confidently assumed that IRD had produced a real benefit. This analysis was done by overall adoption across the 18 districts and by three regions (the seven most western districts, five central districts and six eastern districts).

\section{Analysis of the uptake of the COB varieties compared with NRRP varieties}

The adoption of the released or registered COB varieties that were distributed in the IRD was compared with the adoption of the three most contemporaneous released varieties from the national rice research programme (NRRP) namely Loktantra (NR 1487-2-1-2-2-1-1), Mithila (BPI 3-2) and Ram Dhan (OR-367-SP-11) (Table 5). These NRRP varieties provided a rigorous comparison as they had more time to become popular. They were all released in 2006, 2.3 years earlier than the average for the COB varieties (Tables 1). They had been first tested with farmers in either 1994 or 1998 whilst Barkhe 3004, the earliest of the four registered or released varieties, was not tested with farmers until 2004.

The analysis was first done on the proportion of the rice area (\%) occupied by each of these seven varieties. The rice areas were compared for the 2008 baseline survey of 1605 households, the 2011 survey of 1318 households that had received IRD kits in 2008, and the 2011 survey of 469 households resampled from the 2008 baseline survey (see the first paper in this series for details). To remove the effect of differences in sample number amongst districts, they were given equal weights by calculating the district values and then averaging them (i.e., to give the mean of district values).

The frequency of households growing each COB and NRRP variety was also calculated to remove variation associated with the small areas occupied by the COB varieties. These were inevitably low, because most IRD kits were distributed in 2009 
Table 6. The area under COB varieties and the number of IRD kits of $2 \mathrm{~kg}$ required to increase adoption by 1 ha in seven western districts, five central districts and six eastern districts of the Terai (from a survey for adoption in 2011 of a total of 1787 households comprising 1381 households who received IRD kits in 2008 and 469 households sampled from the 2008 baseline households and interviewed again in 2011). For survey details, see paper 1 in this series.

\begin{tabular}{lcccc}
\hline & Sunaulo Sugandha & Barkhe 3004 & Barkhe 2014 & Mean \\
\hline Western districts (ha) & 5670 & 890 & 2730 & 3100 \\
Central districts (ha) & 3910 & 2840 & 3420 & 3390 \\
Eastern districts (ha) & 1030 & 3420 & 10130 & 4860 \\
All 18 districts (ha) & 10610 & 7150 & 16280 & 11350 \\
Western districts IRD kits per ha (no) & 2.40 & 8.47 & 1.23 & 4.0 \\
Central districts IRD kits per ha (no) & 3.60 & 4.51 & 0.32 & 2.8 \\
Eastern districts IRD kits per ha (no) & 2.08 & 3.97 & 0.46 & 2.2 \\
All 18 districts kits per ha (no) & 2.81 & 2.74 & 0.56 & 2.7 \\
Increase best region over worst (factor) & 1.7 & 2.1 & 3.8 & 1.9 \\
\hline
\end{tabular}

*Improvement over best versus worst region e.g., 1.7 times more area of Sunaulo Sugandha adopted from IRD distribution in eastern districts compared with central districts.

and 2010 allowing only one or two seasons for farmers to multiply varieties from farm-saved seed before the survey for 2011. The analysis, using the mean of district values (see above), was first done separately for LI-BIRD and FORWARD for each survey (baseline 2008, baseline resurvey 2011, IRD 2011) and for the two 2011 surveys combined. We determined the average adoption of the four released or registered $\mathrm{COB}$ varieties, the three released $\mathrm{COB}$ varieties and the three released NRRP varieties.

The analysis was then done for 2011 alone by individual variety for each of the 18 districts. This used the total sample of 1783 households by combining the 465 households from the baseline resurvey and the 1318 households from the IRD (for details, see paper 1 in this series). We combined these two surveys for 2011 (IRD and baseline resurvey) to make the comparison of COB with NRRP varieties more rigorous. This reduced the overall intensity of IRD by including data from baseline VDCs where no IRD had taken place but where IRD could have resulted in adoption through farmer-to-farmer seed spread.

\section{RESULTS}

\section{Cost effectiveness of IRD}

For the three released $\mathrm{COB}$ varieties, the number of IRD packets to achieve earlier adoption on 1 ha varied from 0.6 to 4.7 (Table 6). One hectare of earlier adoption per 75 IRD kits is assumed to be the break-even point where cost equal benefits (see materials and methods). Even for the least popular variety, Barkhe 3004, this will be achieved even if the area under was 16 times smaller than estimated or the costs of IRD 16 times more than assumed. For the most popular variety, Barkhe 2014, adoption could be 125 times smaller or costs 125 times higher.

The efficiency of the IRD (area (ha) adopted versus number of kits supplied) varied by region. Averaged across the three varieties the efficiency increased from west to 
Table 7. The adoption in 2008 or 2011 of seven varieties (three NRRP varieties and four COB varieties) by proportion $(\%)$ of rice area based on the means of district values (see Materials and Methods). Means shown for three NRRP and three COB varieties. From three surveys (for 2008 adoption 1605 households in baseline survey; for 2011 adoption 1381 households who received IRD kits in 2008 and 469 households sampled from the 2008 baseline households and interviewed again in 2011). For survey details, see paper 1 in this series. Varieties shown in order of the extent of adoption in the IRD survey.

\begin{tabular}{|c|c|c|c|c|c|c|c|c|c|}
\hline \multirow[b]{2}{*}{ Variety } & \multicolumn{3}{|c|}{$\begin{array}{c}\text { IRD survey } 2011^{*} \\
(\% \text { area })\end{array}$} & \multicolumn{3}{|c|}{$\begin{array}{l}\text { Resurvey } 2011^{\dagger} \\
\quad(\% \text { area })\end{array}$} & \multicolumn{3}{|c|}{$\begin{array}{l}\text { Baseline } 2008 \\
\quad(\% \text { area })\end{array}$} \\
\hline & $\mathrm{W}$ & $\mathrm{E}$ & All & $\mathrm{W}$ & $\mathrm{E}$ & All & $\mathrm{W}$ & $\mathrm{E}$ & All \\
\hline Barkhe 2014 (COB) & 0.8 & 2.4 & 1.8 & & 0.7 & 0.4 & & & \\
\hline Rham Dhan (NNRP) & 2.6 & 1.2 & 1.7 & 1.3 & 0.1 & 0.6 & 0.6 & & 0.3 \\
\hline Sunaulo Sugandha (COB) & 1.5 & 1.1 & 1.4 & 0.3 & & 0.1 & & 0.2 & 0.1 \\
\hline Barkhe 3004 (COB) & 0.2 & 1.2 & 0.9 & & & & & & \\
\hline Mathila (NRRP) & 0.3 & 0.8 & 0.6 & & 0.2 & 0.1 & & & \\
\hline Barkhe 1027 (COB) & 0.2 & 0.4 & 0.3 & 0.3 & & 0.1 & & & \\
\hline Loktantra (NRRP) & 0.6 & & 0.2 & 0.5 & 0.1 & 0.3 & & & \\
\hline Three COB varieties ${ }^{\ddagger}$ & 4.3 & 3.5 & 4 & 1.6 & 0.1 & 0.7 & & & \\
\hline Three NRRP varieties & 1.3 & 3.6 & 2.7 & 0.3 & 0.9 & 0.6 & & & \\
\hline
\end{tabular}

* Survey of randomly selected 1318 households that had received an IRD kit in 2008.

${ }^{\dagger}$ Survey of a randomly selected sample from the baseline survey of 2008.

${ }^{\ddagger}$ Excluding Barkhe 1027 to have equal numbers of NRRP and COB varieties.

east (from 4.0 to $2.2 \mathrm{kits} \mathrm{ha}^{-1}$ ). This is likely reflecting the later maturity of the COB varieties that are less adapted to the west (see supplementary Table S2 first paper of this series, available online at http://dx.doi.org/10.1017/S0014479716000624). In the household surveys, the highest average age of the more widely adopted varieties in both 2008 and 2011 was in the central districts (first paper in this series) indicating that this region might be the most resistant to varietal change. However, the effectiveness of IRD in these districts was about average when all three varieties were considered and at its most efficient for Barkhe 2014. This variety showed the greatest regional differences with only 0.32 kits producing 1 ha of adoption in the central districts compared with nearly four times as many required in the west.

\section{Adoption of four COB varieties compared with NRRP varieties following the IRD programme}

In 2008, only one of the four released or registered COB varieties and only one of the three released NRRP varieties were grown by households in the baseline survey in less than $1 \%$ of the area (Table 7). By 2011, the area under these seven varieties had increased and the COB varieties promoted in the IRD programme were higher in area than the recent NRRP varieties. No variety was grown on a large area; only Ram Dhan from NRRP and Barkhe 2014 and Sunaulo Sugandha from COB were grown on more than $1 \%$ of the rice area.

As the adoption of all these recent NRRP and COB varieties by area was modest, the frequency with which they were grown (by proportion (\%) households) was considered to remove the variation caused by differing farm sizes amongst the households surveyed. We compared household adoption for the IRD programme of 
Table 8. Adoption in 2011 in LI-BIRD and FORWARD districts. Mean of three or four COB varieties and three new NRRP varieties (\% of households $(\mathrm{hh}){ }^{*}$ ) based on the means of district values (see Materials and Methods). From a survey for adoption in 2011 of 1381 hh who received IRD kits in 2008 (IRD survey) and 469 hh sampled from the 2008 baseline households and interviewed again in 2011 (baseline resurvey) and a total of 1787 households (both surveys). For survey details, see paper 1 in this series.

\begin{tabular}{lccc}
\hline 2011 survey and varieties analysed & $\begin{array}{c}\text { LI-BIRD mean } \\
\text { of } 11 \text { district } \\
\text { values }(\% \mathrm{hh})\end{array}$ & $\begin{array}{c}\text { FORWARD mean } \\
\text { of seven district } \\
\text { values }(\% \mathrm{hh})\end{array}$ & $\begin{array}{c}\text { Mean of 18 } \\
\text { district values } \\
(\% \mathrm{hh})\end{array}$ \\
\hline Baseline resurvey (four COB varieties) & 17.2 & 7.9 & 13.6 \\
IRD survey (four COB varieties) & 21.6 & 16.6 & 19.7 \\
Both surveys ${ }^{\dagger}$ (four COB varieties) & 20.6 & 14.1 & 18.1 \\
Both surveys (three COB varieties $\left.^{\ddagger}\right)$ & 17.8 & 11.2 & 15.2 \\
Both surveys (three NRRP varieties) & 9.5 & 5.8 & 8.1 \\
\hline
\end{tabular}

${ }^{*}$ Households growing at least one COB variety i.e., $\mathrm{HH}$ growing more than one COB variety counted just once (same calculation was made for NRRP varieties).

${ }^{\dagger}$ Both baseline resurvey and IRD survey - data combined to give overall mean for all 1787 households.

${ }^{\ddagger}$ Excluding Barkhe 1027 to compare equal numbers of COB varieties and NRRP varieties.

LI-BIRD ( $70 \%$ of the total IRD packets) with that of FORWARD. In the case of LI-BIRD, there was only a small difference between the adoption of the four COB varieties in the IRD villages and the resurvey in the baseline villages from 21.6 to $17.2 \%$ (Table 8 ). In the more intensive LI-BIRD programme, there would have been greater opportunity for farmer-to-farmer spread from IRD to baseline villages and some of the baseline villages would have had IRD distribution. In the less intensive FORWARD programme, these factors would be reduced so there was a greater reduction in adoption in the baseline villages compared with and IRD villages (16.6 to $7.9 \%$ ).

In both the LI-BIRD and FORWARD districts, the adoption of the three GOB varieties was higher than that of the three NRRP varieties. Over all of the 18 districts nearly twice as many households grew the three released COB varieties compared with the three released NRRP varieties (15.2 versus $8.1 \%$ of households).

The resurvey of baseline villages was made to compare adoption in villages with little or no IRD to those where the IRD took place. However, given the substantial adoption of $\mathrm{COB}$ varieties in the baseline villages, we combined both surveys to analyse adoption of individual varieties by district. The adoption in 2011 of the COB and NRRP varieties by the proportion of households growing them varied greatly across districts and between varieties (Figure 2). Of the three NRRP varieties, Ram Dhan was clearly the most accepted but was very unevenly distributed as it was very popular in Nawalparasi and Dhanusha and not found at all in several districts. Loktantra and Mithila were found in only a few districts. The three COB varieties were more widely distributed across districts and Sunaulo Sugandha and Barkhe 2014 were the most popular of them. Barkhe 2014 was the most evenly distributed of any variety and was grown by more than $5 \%$ of the households in nine districts. 


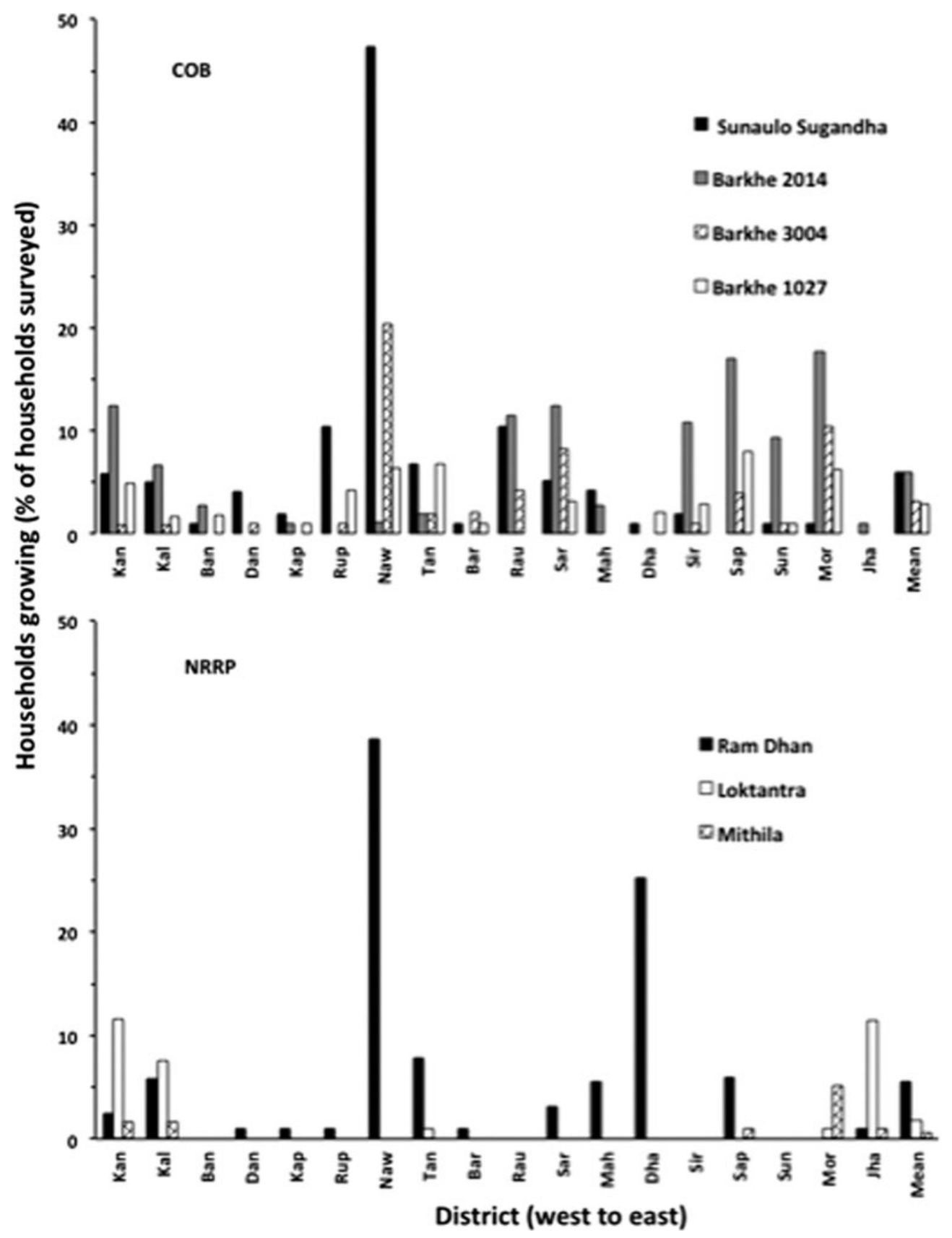

Figure 2. Adoption as proportion of households in the survey of most popular varieties from the COB programme (top) and the three recent NARC varieties (bottom) across 18 districts from the 1783 households surveyed in 2011 (IRD survey and baseline resurvey). 
There were generally weak correlations between the adoption of a variety and the intensity of its supply by district. The correlations were low and non-significant for Barkhe $2014\left(r^{2}=0.05\right)$ and Barkhe $3004\left(r^{2}=0.14\right)$. The highest correlation was for Sunaulo Sugandha $\left(r^{2}=0.47, P<0.001\right)$ although this was largely due to high values in Nawalparasi - without Nawalparasi the $r^{2}$ was $0.29(P<0.05)$. For Barkhe 1027, the correlation was low, $r^{2}=0.25$, but significant $(P<0.05)$.

\section{DISGUSSION}

The IRD approach: $i$ is not the same as minikits and front line demonstrations

IRD differs in many ways from the 'minikits' used in south Asia where extension services distribute seed of a recommended variety along with fertilisers and a recommended package of agronomic practices. In IRD, no such recommendations are made, instead there is simply a leaflet describing the varietal characteristics. There is no supply of inputs such as fertiliser making the IRD much cheaper so more kits can be distributed for the same cost. Farmers within a village are also given a choice of varieties not just one recommended variety. In addition, emphasis is placed on speed in IRD so the initial kits are comprised of truthfully labelled seed rather than certified seed that takes longer to produce. Developing countries are increasingly allowing the sale of truthfully labelled seeds (the label describes legally enforceable minimum standards of e.g., germination and purity) to provide a more rapid and flexible means of seed supply (Lillesø et al., 201 1; Tripp, 2001, 2006).

Perhaps, more important is a change in the model of research and extension. In the conventional approach, research (creation of technology) is done by breeders followed by extension (transfer of technology) done by extension workers in a government department of agriculture. This is a two-stage transfer of technology model where the breeder's responsibility ends with the production of breeder seed. In a more participatory IRD approach, research and extension is done in parallel and a breeder is not just responsible for breeding new varieties but also helps in their promotion. Breeders become responsible to the point of delivery not just to the point of release and have to work closely with colleagues in the extension services.

IRD has many more packets than minikits but still has to be limited in scale so that it does not replace the need for commercial seed production. However, it also has to be on a large enough scale to spark commercial production by creating a demand for seed of the new varieties. For the required balance, the IRD programme should include many farmers and villages but be limited in both duration, to just a few years, and in seed quantity, by distributing only 'sample sizes' of seed (although nothing can be done to prevent groups of farmers pooling the seed if they decide to do this).

\section{The IRD approach: IRD is complementary to PVS}

For the many reasons discussed in the first paper in this series, the most popular varieties in the Nepal Terai are not equally distributed across the districts in Nepal. The recent $\mathrm{COB}$ varieties and the newer NRRP varieties showed this same uneven pattern (Figure 2.). Adoption patterns were so specific that no rice variety was grown 
in all districts, and most were widely grown in just a few adjacent districts. This presents a challenge for testing new varieties appropriately. A varietal testing system is designed to provide data to support official release and because of the costs involved, are conducted at only a few locations. Hence, trials across a limited number of locations will not provide sufficient information to know in which districts or regions the variety is most adapted. An IRD programme, such as the one described here, is the only means of providing - in only a few seasons - information sufficient to target accurately where varieties should be popularised. Allowing many years for farmer preferences and market forces to play out would also provide this information but, unlike IRD, would not accelerate adoption.

PVS and IRD could be considered as very similar - they both test varieties with farmers who grow them in their own fields and can produce comparable results (Joshi and Witcombe, 2002). However, they can fulfil very different functions. PVS devotes resources to evaluation to give statistically analysable data on varietal performance and farmers' preferences. It thus provides an initial test on whether it is of value to spend resources on popularising a variety. IRD spends few resources on formal evaluation but can rapidly determine which varieties are worth concentrating on through anecdotal methods. It can determine more precisely where they should be marketed as the tests are greater in number and over a wider area.

A great advantage of IRD over PVS is that it also provides the mechanism for the essential test marketing of a variety on a large scale. IRD can create sufficient adoption to produce the large quantities of seed that rice millers need to purchase and process a new variety. The real market value of a variety and its post-harvest qualities are then known. IRD, unlike PVS, gives an estimate of a variety's strengths and weaknesses in the market in competition with varieties having an established demand.

\section{Cost effectiveness of IRD}

The IRD programme accelerated adoption as farmers were growing the COB varieties on a significant scale in the unusually short period of only 3 years after their official release. It was also extremely cost effective as the number of IRD packets to create 1 ha of early adoption was low (Table 6), so benefits to farmers were much higher than the cost of distribution of the IRD seed. The cost effectiveness would remain even under the unlikely assumptions that most of the adoption recorded was derived from seed sources other than IRD kits or the costs of IRD were many times more than estimated. Moreover, all of these scenarios conservatively assume benefits over a single year. IRD accelerates adoption by several years, not just one, so the benefits accumulate over seasons. Hence, only under the most pessimistic set of assumptions that greatly increase costs and greatly increase the number of kits required to accelerate adoption would IRD fail to give an attractive benefit cost ratio. However, the costs of IRD are borne by the public sector (along with all publicsector plant breeding and public-sector agricultural extension) whilst the benefits are accrued by the private sector. 
In the short-term 'Research into Use' project, the distribution of IRD sets was determined by seed availability and a desire to offer farmers a wide choice of varieties. The cost effectiveness of the IRD proved to be high even though this was not a primary objective. Large quantities of seed (an average of $8 \mathrm{t}$ of seed per district) were distributed to improve the reliability of the research results. In an extension approach better targeting can substantially reduce the quantities of seed required given the findings that, for example, there was a 3.8 fold difference in the impact of distributing the seed of Barkhe 2014 according to where it was distributed (Table 6). Finding out the areas where particular varieties are most accepted could be used to greatly increase cost effectiveness. This is best done by surveys after each season of IRD kit distribution, and if done 2-3 months after harvest they allow sufficient time for post-harvest evaluation.

An efficient IRD system that is designed predominantly for extension and not research ought to produce a significant correlation between the distribution of IRD kits and adoption levels across the districts. However, in our research programme, there was a low correlation between adoption and distribution by district caused by varieties being distributed in districts where they were poorly accepted. We had insufficient information to prioritise the districts where a variety was most liked by farmers. We were also unable to prioritise amongst the COB varieties as there was limited seed and we also did not know which would be most accepted - amongst the four varieties considered in detail only $10 \%$ of the IRD kits were of Barkhe 2014 but it was adopted as much as Sunaulo Sugandha (Table 7) that had 35\% of the kits. The earlier Barkhe 2014 fitted into more farming systems than the specialist longduration, aromatic Sunaulo Sugandha (Table 1). Barkhe 1027 with 15\% of the IRD kits had an almost equal adoption rate to that of Barkhe 3004 the most distributed variety with $39 \%$ of the kits.

Priorities determined by simple amount of acceptance may differ when the superiority of the individual varieties is also considered. For example, the lower uptake of Sunaulo Sugandha per IRD kit compared with Barkhe 2014 may be more than offset by the greater financial gains per hectare provided by the better market price of aromatic Sunaulo Sugandha over non-aromatic varieties such as Barkhe 2014.

\section{A comparison between the results of IRD with conventional extension}

The uptake of three COB varieties was compared with three NRRP varieties released in 2006 for the Terai and promoted through the conventional system. This could not be a controlled experiment. Despite this, we had to make the comparison because if the adoption of the $\mathrm{COB}$ varieties were to be substantially lower than that of the conventionally promoted varieties, it would cast serious doubts on the efficacy of IRD. Amongst the many factors that could have influenced the differences in the adoption of the COB and NRRP varieties, it was only possible to consider the time available for popularisation and the extent of seed supply. Other factors could not be analysed that could be crucial. For example, we have no data on differences in acceptability between the COB and the NRRP varieties. 
The varieties from NRRP have had longer to become popular and have been supported by extension through DADOs. They have also been under greater amounts of official seed multiplication as indicated by breeder seed demand.

The NRRP varieties were released, on average, over 2 years earlier than the COB varieties (Tables 1 and 5) and were tested in farmers' fields many years before them. In projects to support community-based seed producers, Ram Dhan and Mithila were already under multiplication in groups as early as 2002, 4 years before their release in 2006 and 8 years before the IRD programme began. Ram Dhan was identified as a farmer-preferred variety through on-farm farmers' field trials as early as 1994 (NARC, 2006).

Seed of the NRRP varieties was supplied in the formal seed production chain system to a greater extent than the COB varieties. In 2011, the seed indents by DADOs (as a percentage of total demand for rice foundation seed) was $9.1 \%$ for the three NRRP varieties versus $2.7 \%$ for the three COB varieties, $6.3 \%$ versus $1.6 \%$ by private seed companies and $13.4 \%$ versus $3.7 \%$ for community-based seed production groups and cooperatives. For the $\mathrm{COB}$ varieties, the only indents were for Barkhe 3004 and Sunaulo Sugandha (mostly for the latter). Barkhe 2014 and Barkhe 1027 do not appear in seed indent for 2011 as they were only released in that year.

Despite these differences in time to be popularised and amounts of seed supplied in the formal system, the adoption of the $\mathrm{COB}$ varieties was higher than those from NRRP. The area under the COB varieties was 48\% higher than for NRRP varieties ( $4 \%$ versus $2.7 \%$ ) in the IRD survey and $17 \%$ higher in the baseline resurvey $(0.7 \%$ versus $0.6 \%$ ) (Table 7). The proportion of households adopting $\mathrm{COB}$ varieties was $88 \%$ higher $(15.2 \%$ of households versus $8.1 \%$ ) (Table 8 , Figure 2$)$. The adoption of NRRP varieties was also more limited by district - COB varieties were found in all 18 districts whilst none of the recent NRRP varieties were found in four districts and eight districts had only Ram Dhan.

The higher adoption of the COB varieties compared with NRRP varieties, rather than a negative finding of a substantially lower one, means that this comparison casts no doubts on the conclusion (based on the data in Table 6) that IRD is cost effective.

\section{IRD does not determine the eventual acceptance of varieties}

The initial acceptance of a COB variety in the IRD programme does not mean that the variety will eventually become popular. IRD kits must inevitably have a direct, short-term influence on increasing the frequency with which a variety is grown. IRD provides the basis on which many farmers can decide on whether they will continue to grow or drop a variety and whether they will distribute seed of it to others and on what scale. Farmers' decisions become increasingly more important than the amounts of seed supplied in IRD and eventually varieties without significant advantages will no longer be grown.

Both the COB and NRRP varieties had popular and much less popular varieties showing that neither system can guarantee the success of all the varieties it releases. Of the NRRP varieties, Ram Dhan was by far the most popular overall and Mithila 
clearly the least preferred. Of the COB varieties, Barkhe 2014 and Sunaulo Sugandha were more popular. The high distribution of Barkhe 3004 and its low adoption showed farmers were much less enthusiastic about this variety. It had a good yield and useful agronomic traits but clearly its advantages were insufficient for it to be adopted in competition with established varieties.

Varieties need a sustainable seed supply by seed producers multiplying and marketing seeds. The two most accepted varieties in the programme, Sunaulo Sugandha and Barkhe 2014, are being produced after the IRD programme without project intervention. For example, in 2015, Sunaulo Sugandha was produced by Unnat seed producers in Chitwan District whilst Barkhe 2014 was produced by Salhesfulbari seed producer group Siraha (N. P. Khanal pers. comm.). The two least popular of the COB varieties (Barkhe 3004 and Barkhe 1027) did not find such champions. As discussed by Witcombe et al. (2010) and Joshi et al. (2012), it is much easier and less risky to produce seed of varieties that are already popular. Farmers are very familiar with already popular varieties so farmers demand seed of them. A riskaverse seed supply industry meets this demand and only ventures into the production of new varieties if they are very confident of adequate demand.

\section{GONGLUSIONS}

Rice production in Nepal is constrained by farmers growing old rice varieties. They fail to gain the benefits of growing newer varieties that have had more generations of plant breeding improvement (first paper in this series). Clearly, the participatory extension method of IRD accelerates the adoption of new varieties whilst providing information on their overall acceptability and the areas in which they are most preferred. The costs of IRD are far smaller than the benefits to be gained by farmers from growing new varieties and less than the costs of breeding the new varieties. It makes little sense to invest substantial resources in plant breeding research and then fail to ensure that farmers rapidly take up the expensive products of this research.

The scale of the potential impact of IRD is illustrated by Hardinath-1, released in 2004, that was the sixth most popular variety overall in 2011 and the most popular of all recent varieties (first paper in this series). A substantial cause of this success was projects using PVS and IRD methods that supplied $140 \mathrm{t}$ of seed of Hardinath-1 sufficient to sow about 3600 ha from 2000 to 2006 (Joshi et al., 2012). In addition, in the RiUP project reported here, 3340 IRD sets of Hardinath-1 were distributed from 2008 to 2011.

Ghimere et al. (2015) examined that factors that influenced whether farmers adopted new rice varieties in Nepal. They concluded that variables relating to access to seed and extension were important and stated 'increased emphasis on information dissemination, extension demonstration, and farmers' participatory research and training programmes to popularise new rice varieties and enhance their adoption rate are required'. Our results strongly endorse this view and have demonstrated how IRD provides a simple means of improving the dissemination of information and seed. IRD can greatly increase the rate of adoption of new rice varieties and because of its 
cost effectiveness, it is certainly one of the most effective interventions for increasing agricultural productivity in the developing world.

Acknowledgements. This paper is an output from projects funded by the Plant Sciences Research Programme and the Research into Use Programme of the UK Department for International Development (DFID) for the benefit of developing countries. The views expressed are not necessarily those of the DFID. The authors would like to thank all the farmers' groups in Nepal for their essential role in this research. Many staff from LI-BIRD, FORWARD and SUPPORT Foundation greatly contributed to this research.

\section{SUPPLEMENTARY MATERIALS}

For supplementary material for this article, please visit http://dx.doi.org/10.1017/ S0014479716000624

\section{REFERENGES}

Ghimire, R., Huang, W.-C. and Shrestha, R. B. (2015). Factors affecting adoption of improved rice varieties among rural farm households in Central Nepal. Rice Science 22:35-43.

Gyawali, S., Joshi, K. D. and Witcombe, J. R. (2002). Participatory plant breeding in low-altitude production systems in Nepal. In Breeding Rainfed Rice for Drought-Prone Environments: Integrating Conventional and Participatory Plant Breeding in South and Southeast Asia. Proceedings of a DFID Plant Sciences Research Programme/IRRI Conference, 12-15 March 2002, IRRI, Los Baños, Laguna, Philippines, 8-11 (Eds J. R. Witcombe, L. B. Parr and G. N. Atlin). Bangor and Manila: Department for International Development (DFID) Plant Sciences Research Programme, Centre for Arid Zone Studies (CAZS) and International Rice Research Institute (IRRI).

Joshi, A. and Witcombe, J. R. (1996). Farmer participatory crop improvement. II. Participatory varietal selection, a case study in India. Experimental Agriculture 32:461-477.

Joshi, K. D., Devkota, K. P., Harris, D., Khanal, N. P., Paudyal, B., Sapkota, A. and Witcombe, J. R. (2012). Participatory research approaches rapidly improve household food security in Nepal and identify policy changes required for institutionalisation. Field Crops Research 131:40-48.

Joshi, K. D., Musa, A. M., Johansen, C., Gyawali, S., Harris, D. and Witcombe, J. R. (2007). Highly client-oriented breeding, using local preferences and selection, produces widely adapted rice varieties. Field Crops Research 100:107116.

Joshi, K. D. and Sthapit, B. R. (1990). Informal research and development (IRD): A new approach to research and extension. LARC Discussion Paper 1990/4. Pokhara, Nepal: Lumle Agriculture Research Centre.

Joshi, K. D., Subedi, M., Rana, R. B., Kadyat, K. B. and Sthapit, B. R. (1997). Enhancing on-farm varietal diversity through participatory varietal selection: A case study for Chaite rice in Nepal. Experimental Agriculture 33:335-334.

Joshi, K. D. and Witcombe, J. R. (2002). Participatory varietal selection in rice in Nepal - a comparison of two methods by farmer's selection and varietal adoption. Euphytica 127:445-458.

Lillesø, J. B. L., Graudal, L., Moestrup, S., Kjær, E. D., Kindt, R., Mbora, A., Dawson, I., Muriuki, J., Ræbild, A. and Jamnadass, R. (2011). Innovation in input supply systems in smallholder agroforestry: Seed sources, supply chains and support systems. Agroforestry Systems 83:347-359.

NARC (2006). NARC Newesletter. Vol 13, No. 2. Kathmandu, Nepal: Nepal Agricultural Research Centre, p. 8.

Tripp, R. (2001). Seed Provisioning and Agricultural Development: The Institutions of Rural Change. London, UK: Overseas Development Institute.

Tripp, R. (2006). The Case for Foundation Seed Enterprises in Sub-Saharan Africa. London, UK: Overseas Development Institute.

Witcombe, J. R., Devkota, K. P. and Joshi, K. D. (2010). Linking community-based seed producers to markets for a sustainable seed supply system. Experimental Agriculture 46:425-437. 
Witcombe, J. R., Gyawali, S., Subedi, M., Gyawali, S., Virk, D. S. and Joshi, K. D. (2013). Plant breeding can be made more efficient by having fewer, better crosses. BMC Plant Biology 13: 22.

Witcombe, J. R., Joshi, A., Joshi, K. D. and Sthapit, B. R. (1996). Farmer participatory crop improvement. I. Varietal selection and breeding methods and their impact on biodiversity. Experimental Agriculture 32:445-460.

Witcombe, J. R., Joshi, K. D., Gyawali, S., Musa, A. M., Johansen, C., Virk, D. S. and Sthapit, B. R. (2005). Participatory plant breeding is better described as highly client-oriented plant breeding. I. Four indicators of client-orientation in plant breeding. Experimental Agriculture 41:299-319.

Witcombe, J. R. and Virk, D. S. (2001). Number of crosses and population size for participatory and classical plant breeding. Euphytica 122:451-462. 